RASĀYAN J. Chem.

Vol. 14 | No. 2 |728-734| April - June | 2021

\title{
PRODUCTION OF ELECTROPLATED RHENIUM COATINGS USING PULSATING CURRENTS
}

\author{
J. Bautista-Ruiz ${ }^{1}$, W. Aperador ${ }^{2} \bowtie$ and J.C. Caicedo ${ }^{3}$ \\ ${ }^{1}$ Engineering Faculty, Universidad Francisco de Paula Santander, \\ San José de Cúcuta-540005, Colombia \\ ${ }^{2}$ Engineering Faculty, Universidad Militar Nueva Granada, Bogotá-11101, Colombia \\ ${ }^{3}$ Department of Physics, Universidad del Valle, Cali-760034, Colombia \\ ${ }^{\square}$ Corresponding Author: g.ing.materiales@gmail.com
}

\begin{abstract}
Rhenium was the most interesting material because it can be oxidized at high temperatures, so it is a promising applicant in biomedical applications. Its high melting point requires techniques such as electro-coating to produce it in thin-film formation, using a current of $40 \mathrm{~mA} / \mathrm{cm}^{2}$, in a cathode pulse and $4 \mathrm{~mA} / \mathrm{cm}^{2}$, in anodic form, the variation in temperature of the acid electrolytic bath being realized in a range of 60 to $85 \pm 2{ }^{\circ} \mathrm{C}$. The temperature variation of the samples allowed to correlate their response to the degradation phenomenon. The topographical evaluation using atomic force microscopy on the surface of the samples permitted to indicate that a tendency of the roughness to reduce with the increase of the temperature up to $80{ }^{\circ} \mathrm{C}$ existed, an electrochemical evaluation was generated using Tafel polarization curves, immersed in a Ringer's lactate solution with a temperature of $37^{\circ} \mathrm{C}$, has now been subsequently performed using the scanning electron microscope, the surface analysis of the coatings, demonstrating that at deterioration is negligible, but when increasing the temperature to $80^{\circ} \mathrm{C}$, the deterioration is imperceptible when the type of surface damage is unobservable, however in the case of $85^{\circ} \mathrm{C}$ the deterioration is observable.
\end{abstract}

Keywords: Rhenium, Pulsating Currents, Corrosion, Morphology.

RASĀYAN J. Chem., Vol. 14, No.2, 2021

\section{INTRODUCTION}

In the last years, there has been an interest in the Rhenium for the development of new biomedical applications, because several authors have reported it as a material with biocompatible applications, where its biocompatibility depends on its surface properties and its structure. ${ }^{1}$ According to this panorama, the investigations around the modifications of the surface in biomaterials, ${ }^{2,3}$ have allowed improving the interaction of the biocompatible alloys with biological fluids, improving the adsorption between the macromolecules, present in the fluid, and the surface of the implant. Among the applications that take advantage of the properties of the coatings obtained by electrodeposition, it is possible to mention surgical tools, dental implants, and prostheses. In addition to their biocompatibility, they have been demonstrated to increase surface hardness and corrosion resistance. ${ }^{4}$

Also, the development of new coatings is constant. ${ }^{5}$ Consequently, the purpose is to investigate the behavior of rhenium coatings, in interaction with a simulated body fluid, to find a system that meets the established biocompatibility requirements, that blocks the release of allergic metal ions and ensures maximum durability in terms of corrosion resistance. ${ }^{6}$ The study of Rhenium remains uncertain because there is very little information regarding the processes of obtaining it and its applications. ${ }^{7}$ Although studies have been reported to indicate that the material is used in a biocompatible environment, most of the research results have focused on technological aspects, properties, and applications in the areas of mechanics, optics, and electronics. ${ }^{8}$ Without hydrolysis, Rhenium is not soluble in water, suggesting the low probability of the existence of $\mathrm{Re}^{+\mathrm{z}}$ ions in solution or minimal concentrations. ${ }^{9}$

The development of novel materials that do not contain vanadium but low percentages of aluminum is currently being promoted to obtain products with better biocompatibility and, consequently, to ensure

Rasayan J. Chem., 14(2), 728-734(2021)

http://dx.doi.org/10.31788/ RJC.2021.1426046

This work is licensed under a CC BY 4.0 license. 
RASĀYAN J. Chem.

Vol. 14 | No. 2 |728-734| April - June | 2021

excellent performance within the human body for long periods. ${ }^{10}$ The biocompatibility in the materials includes the study of the reactions present between the human body and the implant. ${ }^{11}$ The initial phase of contact is related to the interaction with body fluids such as extracellular fluids, spit, or blood and the subsequent adsorption of macromolecules from the fluid in the implant site. ${ }^{12}$

Proteins are involved in this process. Its adsorption plays a vital role in the biocompatibility mechanism related to direct interactions at the interface present. ${ }^{13}$ As a result of low biocompatibility, the material can cause damage to adjacent tissue, which manifests as inflammation. ${ }^{14,15}$

In this research, rhenium coatings were obtained on titanium substrates for use in surgical implants. For this purpose, the effect of the corrosive phenomena of the system on the biocompatible implants, and the structural integrity of the prosthesis were studied. The phenomena of corrosion and dissolution of material can cause the migration of metal ions to the human body, triggering adverse effects due to their biological reaction. The study is complemented by the evaluation of the effect of temperature on the coatings anticorrosive properties of the coatings.

\section{EXPERIMENTAL}

\section{Pulse Current Technique}

The application of the pulse current technique has improved the quality of industrial electroplating processes. The electroplating technique, in comparison with the deposits obtained by the traditional direct current (DC) technique, allows obtaining coatings, with equal or better quality, from solutions in acidic or basic media. Among the advantages of the application of the reverse pulse current (PRC) technique are the use of current densities and process times similar to those used with DC, coatings with fine granulometry with a greater coverage area, decreased porosity, more resistant surfaces. Another significant advantage is the high degree of compaction of the deposited metal, associated with low internal stresses, improvement of the ductility, and hardness of the coatings. The coating with the PRC technique is a bipolar electrodeposition process, in which the DC technique is continually changing with its direction (polarity). The reverse current occurs during the electrodeposition of a metal. The polarity changes automatically and the reverse current (anode) time is a part of the direct current (cathode) time. An additional advantage is increased compatibility of the deposited metal, which is associated with reduced internal stresses, enhanced ductility, and changes in the hardness of the coating obtained.

It is important to highlight that in reverse current electrodeposition of metals, the electricity $q c$ that flows through the electrodes during the cathode period $t_{c}$ is greater than the electricity $q_{a}$ that circulates in the anode period $t_{a}, i_{c} i_{c}>i_{a} t_{a}$. A minimal current is used for anodic bias (separation current) in the production of coatings. During each period in total reverse current, a film of a given thickness is formed. In anodic polarization $\left(t_{a}\right)$, part of that film dissolves.

Additionally, using an alternating polarity current not only increases the current operating density, but the periodic effect of the anodic current on the deposited metal layer results in enhanced protective properties. For some processes, the application of reverse current is the method of obtaining a polished deposit, improved current distribution, and a less porous deposit.

The study of coatings employing reverse current has more variables than those employing direct current, of course, more variables meaning more sophisticated equipment and control, but also, a more extensive range of reservoir features can be selected for a particular application. To represent a pulse-reverse current waveform train, four parameters are known.

- The current density of the peak anodic pulse $\left(J_{a}\right)$

- The cathode pulse time $\left(t_{c}\right)$

- The anodic pulse time $\left(t_{a}\right)$

- The cathode current density $\left(J_{c}\right)$

The average current density is given by:

$$
J_{a v}=\frac{J_{a} t_{a}+J_{c} t_{c}}{t_{c}+t_{a}}\left(\mathrm{~A} / \mathrm{m}^{2}\right)
$$

The average cycle time is as follows: 
RASĀYAN J. Chem.

Vol. 14 | No. 2 |728-734| April - June | 2021

$$
T_{p r c}=\frac{J_{a} t_{a}-J_{c} t_{c}}{J_{a} t_{a}}
$$

\section{Preparation of the Coatings}

Each test requires approximately 2.5 hours including part preparation and electrodeposition time. A threeelectrode cell was used. A $99.99 \%$ pure titanium disc cathode with an area of $1 \mathrm{~cm}^{2}$ was used as a working and counter electrode, and an $\mathrm{Ag} / \mathrm{AgCl} / \mathrm{KCl}$ (saturated) reference electrode. Before the electroplating process, the titanium substrates were cleaned immersed in an ultrasonic bath with detergent for 15 minutes. Subsequently, they were immersed in a solution of hydro-nitric fluoride and deionized water at room temperature for 2 minutes to eliminate oxide residues or surface scales produced in the development of the process. The conditions for Rhenium deposition in general were the following: cathode current density 40 $\mathrm{mA} / \mathrm{cm}^{2}$, cathode pulse time $100 \mathrm{~ms}$, anode pulse current density $4 \mathrm{~mA} / \mathrm{cm}^{2}$, anode pulse time $10 \mathrm{~ms}$ at 10 $\mathrm{pH}=5 \pm 0,1$, and bath temperature varying from 60 to $85 \pm 2{ }^{\circ} \mathrm{C}$.

\section{Characterization of Coatings}

Equipment used for determining surface morphological differences of specimens on the Ra scale was AFM. In practice, the surface area $\mathrm{Ra}$ is determined by the probe tip inside the instrument moving in a linear path on the sample surface and traveling up and down as it moves through irregular parts of the sample. The surface roughness of the samples was measured on the Ra scale by AFM, before and after the electrodeposition process, using an AFM-Nanosurf Easyscan 2 STM equipment.

To characterize its microstructure of films, a NeoScope JMC-5000 scanning electron microscope with up to 40.000 magnification has been used to characterize the surface and examine the processes after corrosion degradation brought about a morphological change in the different samples.

This test provides information on corrosion dynamics by registering the intensity of current passing through an electrochemical system whenever a variable voltage is applied. This voltage increases gradually from a value lower than the corrosion value to a desirable positive value. As a result, the corrosion current "Icorr" and corrosion potential "Ecorr" data are obtained from which it is possible to calculate the corrosion rate of the system. For this analysis, the Gamry model PCI 4 was used, using an electrochemical cell with three electrodes, a platinum counter electrode, and an $\mathrm{Ag} / \mathrm{AgCl}(\mathrm{KCl}$ saturated) reference electrode. All electrochemical tests were performed in a physiological saline solution and at a body temperature of $37^{\circ} \mathrm{C}$, previously evaluated for 1 hour to establish the open circuit potential or stable potential state. The scanning electron microscope technique was then used to observe the evolution of the different samples.

\section{RESULTS AND DISCUSSION}

Figure-1 shows the micrographs obtained by atomic force microscopy based on the deflections of the cantilever from its equilibrium position. With an excellent tip of about $10 \mathrm{~nm}$, with the corresponding characteristics non-contact mode, at a high frequency $330 \mathrm{kHz}$, torque $42 \mathrm{~N} / \mathrm{m}$. It is using a reflective coating, the radius of curvature of the order of $8 \mathrm{~nm}$, located at its end. When approaching the surface of a sample at such distances that forces of the Van der Waals type act, by measuring the cantilever deflection when the tip is moved over the sample surface, and the deflection sensors are position sensitive, the chosen area has been $46.7 \mu \mathrm{m} \times 46.7 \mu \mathrm{m}$ for all the measurements. Therefore, the AFM allowed obtaining images with resolutions of the order of micrometers. ${ }^{16}$ The atomic force microscope operated in a non-contact mode in which the tip vibrates at a given frequency and interacts with the surface atoms the frequency of vibration changes. The statistical analysis of the cantilever deviations permits the quantification of the surface roughness. Figure 1 presents images captured in the non-contact mode for different temperatures. a) $60{ }^{\circ} \mathrm{C}$ (b) $70^{\circ} \mathrm{C}$, c) $80^{\circ} \mathrm{C}$, and d) $85^{\circ} \mathrm{C}$ is deposited on titanium substrates, from which AFM images are extracted using statistical analysis software (SPIP ${ }^{\circledR}$ ), the values of the roughness measurements produced values of $34.52 \pm 0.1 \mathrm{~nm}, 32.77 \pm 0.1 \mathrm{~nm}, 24.11 \pm 0.1 \mathrm{~nm}$, and $39.84 \pm 0.1 \mathrm{~nm}$, for $60{ }^{\circ} \mathrm{C}, 70{ }^{\circ} \mathrm{C}, 80^{\circ} \mathrm{C}$, and $85{ }^{\circ} \mathrm{C}$ respectively, from these results it is possible to deduce that the surface is heterogeneous and shows average roughness values since for $80{ }^{\circ} \mathrm{C}$ a reduction in surface roughness is obtained. ${ }^{17}$

This is attributed to the efficient value that permits the grains formed on the surface to have growth and accommodation, that is due to an increase of the energy of the atoms adsorbed on the surface of the substrate, generating a high number of nucleation sites that leads to a reduction of the grain size, decrease 
RASĀYAN J. Chem.

Vol. 14 | No. 2 |728-734| April - June | 2021

of the roughness of the total surface, and an increase of the nucleation density. ${ }^{18}$ This is important because a smooth surface and a homogeneous composition can decrease the susceptibility to corrosion when these films are exposed to an aggressive environment such as a saline solution that simulates the conditions of the human body.

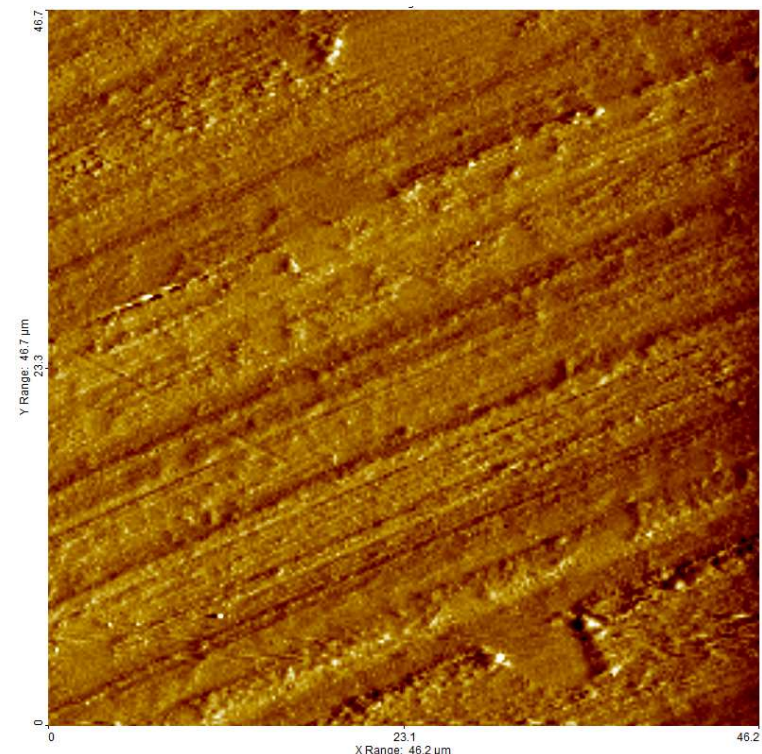

(a)

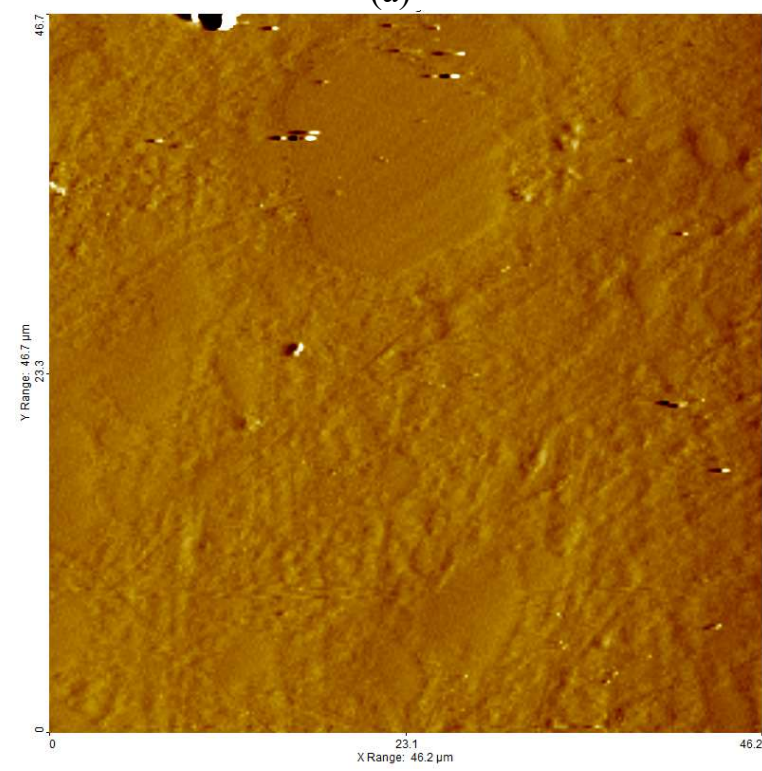

(c)

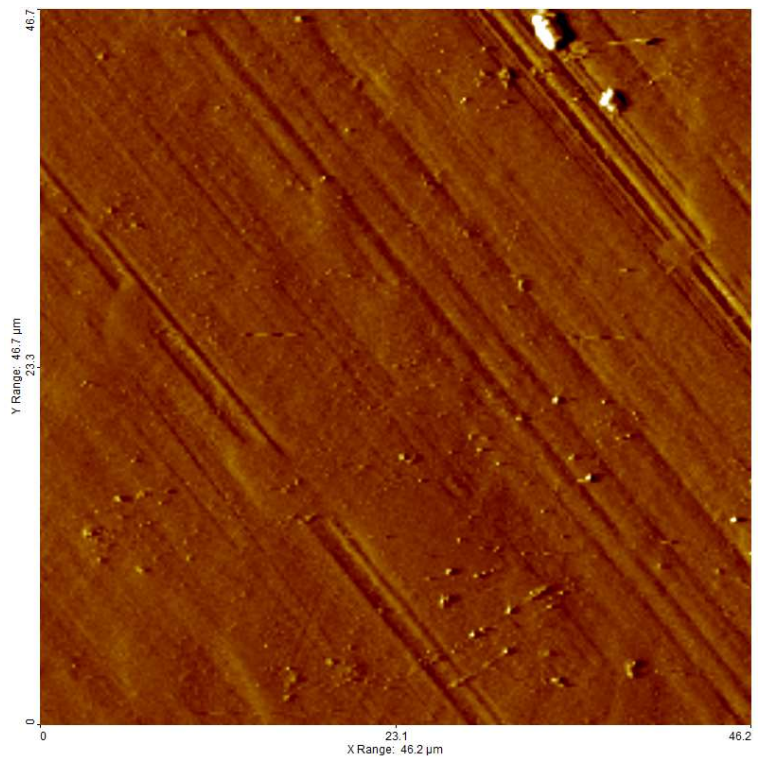

(b)

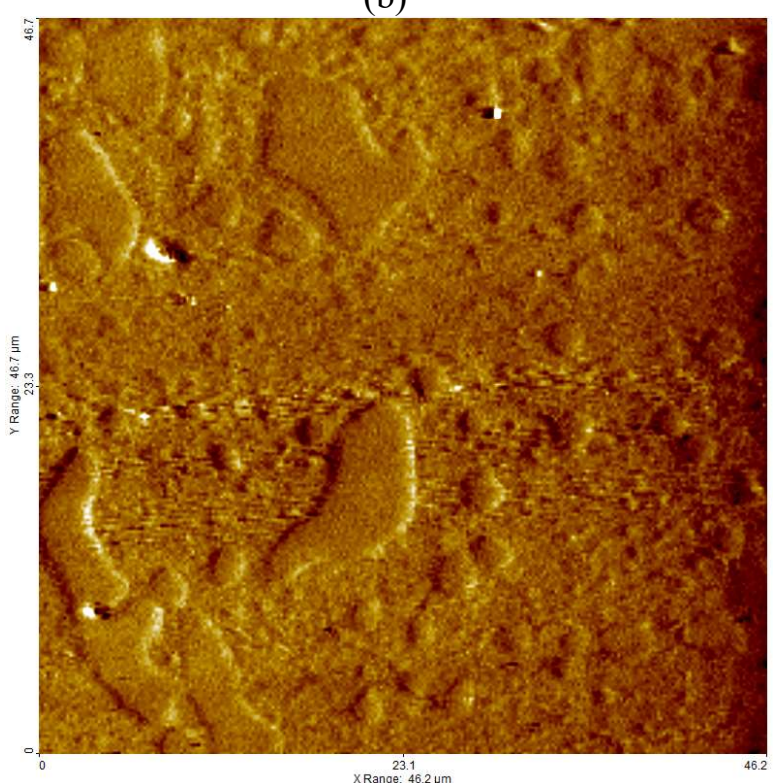

(d)

Fig.-1: Images by the AFM Technique of the Coatings as a Function of Temperature Variation. (a) $60{ }^{\circ} \mathrm{C}$, (b) 70 ${ }^{\circ} \mathrm{C}$, (c) $80{ }^{\circ} \mathrm{C}$, and (d) $85^{\circ} \mathrm{C}$.

Figure-2 represents the cathodic polarization curves of rhenium coatings, determined as a noble material, in the four samples with the variations of temperature, indicating a suitable system for the protection against corrosion phenomena; therefore, the corrosion processes are established as a function of the stability of the temperature variation.

Such materials present a significant resistance to corrosion by chlorides, since there is constant degradation, called electrochemical dissolution, and in neither of the systems is there any attack of localized corrosion, generating an increase in the current density of corrosion at the same potential. ${ }^{19}$ This type of attack only 
RASĀYAN J. Chem.

Vol. 14 | No. 2 |728-734| April - June | 2021

occurs with material operating at a potential (corrosion potential, Ecorr) over a specific critical value, called the pitting potential (Epic). Its values depend on the composition of the metallic material, in the case of the coatings, the barrier effect that decreases the corrosion process in the substrate, which is evidenced by the increase of the corrosion potential for the rhenium coating and its temperature change. ${ }^{20}$ This means that the protective layers are formed, and the corrosion potential is more positive. Thus, the most appropriate temperature used was $80^{\circ} \mathrm{C}$, which is electrochemically nobler than at $60^{\circ} \mathrm{C}, 70^{\circ} \mathrm{C}$, and $85^{\circ} \mathrm{C}$.

Increasing the temperature improves the corrosion resistance, although the stability of these materials depends on the pulsating current as well. ${ }^{21}$ Nevertheless, it is a suitable system to improve its resistance to corrosion in Ringer's lactic solution. In all cases, it significantly decreases the resistance to localized damage due to its noble nature. The electrochemical nature of Ringer's lactate solution is more resistant to corrosion in a solution containing chloride ion. ${ }^{22}$

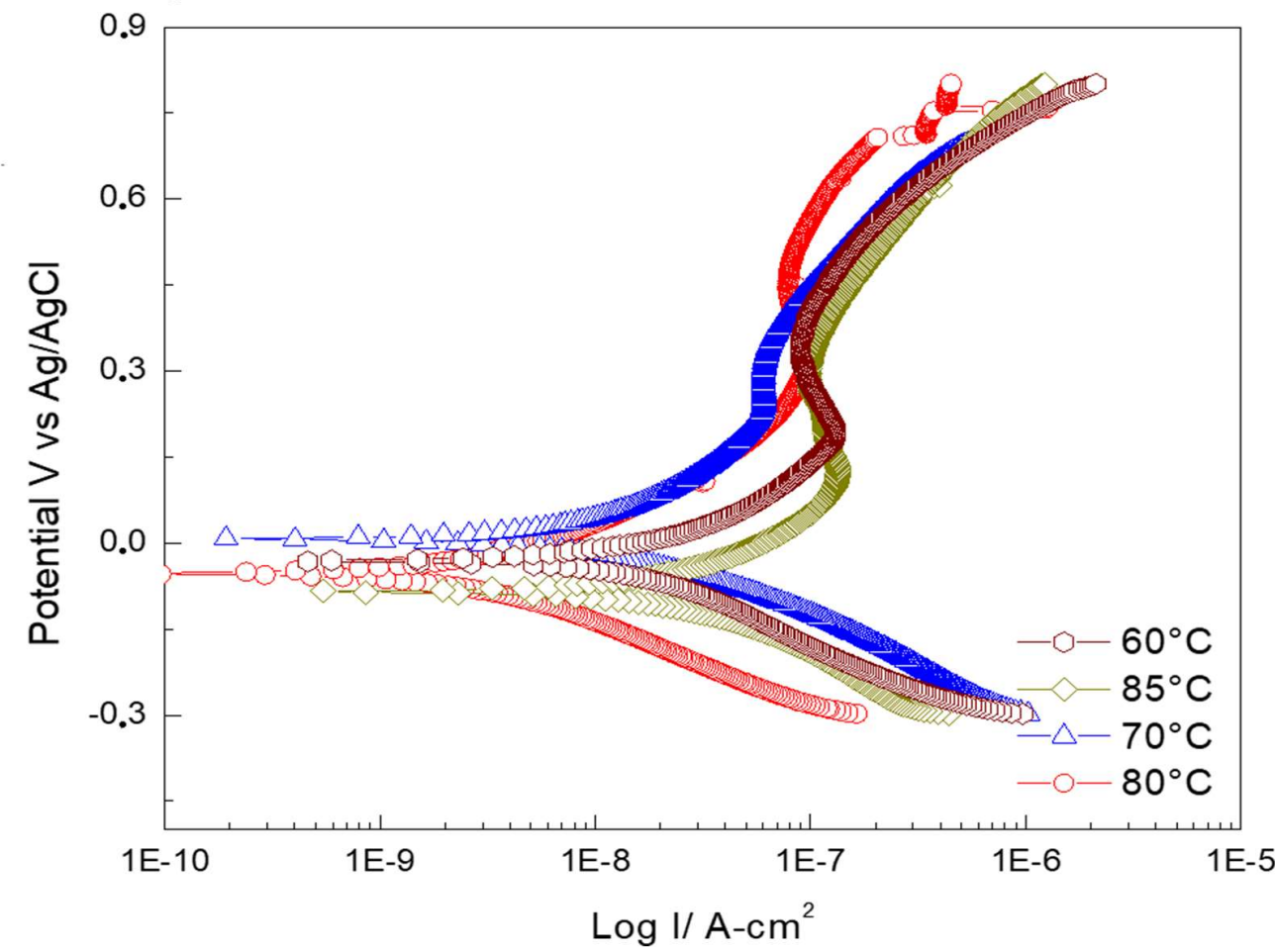

Fig.-2: Potentiodynamic Curves of Coatings with a Temperature Variation of $60^{\circ} \mathrm{C}$ to $85^{\circ} \mathrm{C}$, subjected to a Salt Solution

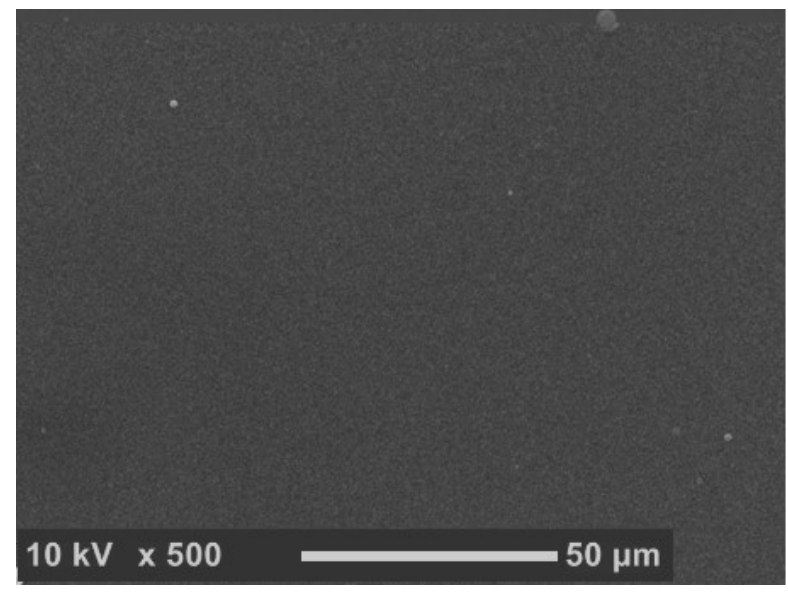

(a)

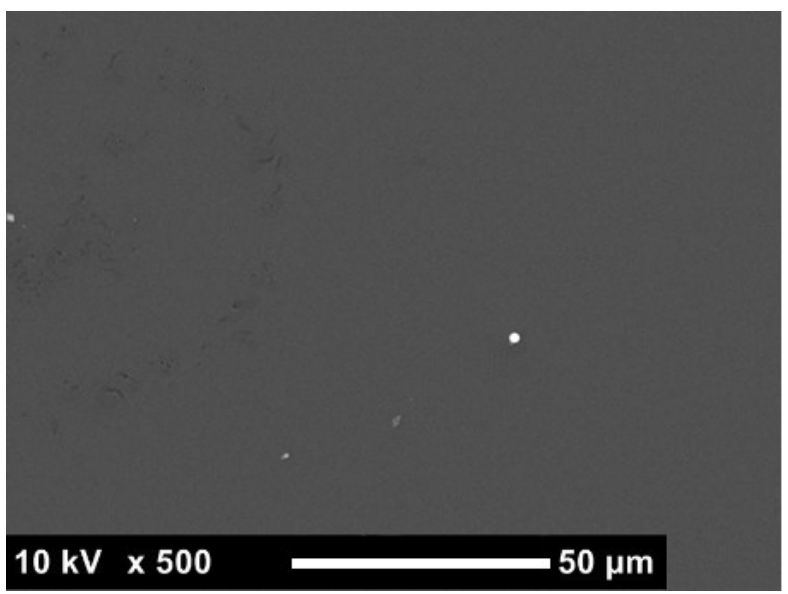

(b) 
RASĀYAN J. Chem.

Vol. 14 | No. 2 |728-734| April - June | 2021

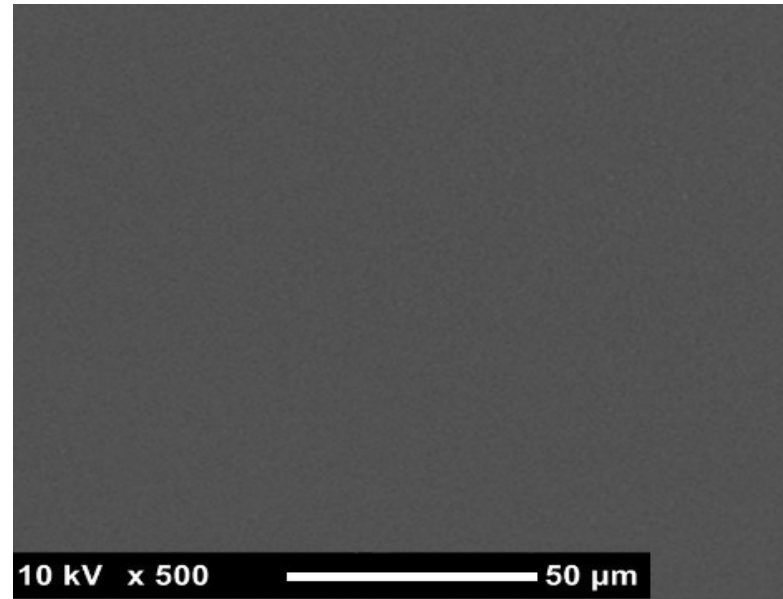

(c)

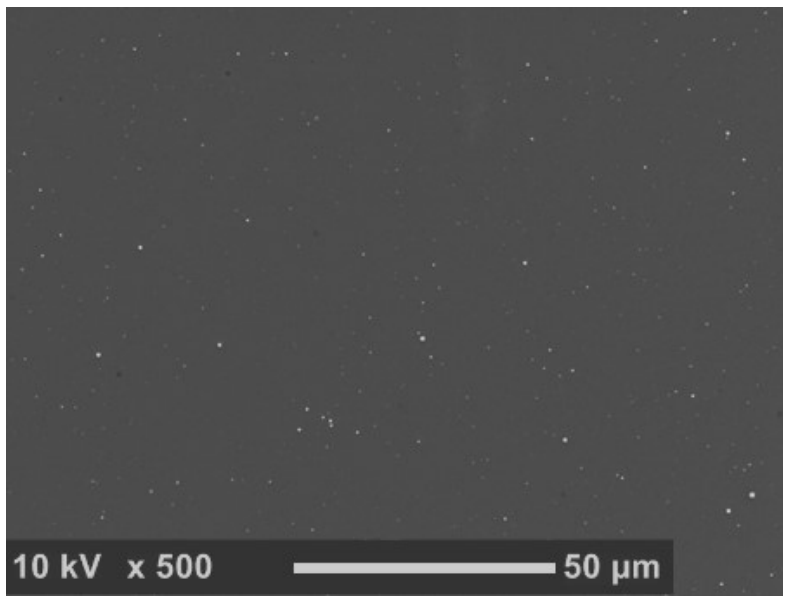

(d)

Fig.-3: Surface Micrographs of the Coatings as a Function of the Temperature of the Rhenium Electrolytic Bath. (a) $60{ }^{\circ} \mathrm{C}$, (b) $70{ }^{\circ} \mathrm{C}$, (c) $80{ }^{\circ} \mathrm{C}$ and (d) $85^{\circ} \mathrm{C}$.

The surface analysis of the coatings was carried out with the assistance of a scanning electron microscope, Fig.-3a, b, c and d. In general terms, it can be seen that, at different temperatures, the characteristic is one of non-deterioration. ${ }^{23,24} \mathrm{An}$ increase in the temperature to obtain the electro-coating generated by the Tafel polarization curves revealed a similar behaviour in the coatings obtained at $60{ }^{\circ} \mathrm{C}$ and $70{ }^{\circ} \mathrm{C}$. The deterioration is minimal, and only some imperfections on the surface are detailed. As the temperature has increased, the morphology has changed as observed with AFM, since a more refined form has been obtained.

Moreover, it became evident of the coating that it has a linear growth tendency with the increase in temperature, but has its limit at $80{ }^{\circ} \mathrm{C}$. The reason behind the increase in temperature is that the material input to the process increases, but it has a turning point at $85^{\circ} \mathrm{C}$. According to these results demonstrated in Fig.-3a, b, c, and d, it is possible to deduce that the mechanism of wear recorded in the coatings is due to a combination of oxidative wear, but that it is not representative because a change in the surface morphology is not evident. ${ }^{25}$

\section{CONCLUSION}

It has been achieved to obtain the Rhenium coatings, using the pulsating current technique, surfaces with adequate texture and low roughness value are observed, obtaining adequate performance on the coating. The corrosion processes are therefore established as a function of temperature, generating the protection, the different values of current density obtained through potentiodynamic polarization curves allowing the barrier effect that decreases the corrosion process in the substrate evident in the increase of the corrosion potential for different temperatures. Therefore, protective layers are produced, increasing the corrosion potential as the temperature rises, obtaining an optimal value at $80^{\circ} \mathrm{C}$ and decreasing it at $85^{\circ} \mathrm{C}$.

\section{ACKNOWLEDGEMENT}

This research was supported by "Vicerectoria de investigaciones Universidad Militar Nueva Granada" under contract ING 3123 validity 2020-2021.

\section{REFERENCES}

1. R. García, A. Paulo, and I. Santos, Inorganica Chimica Acta, 362(12), 4315(2009), DOI:10.1016/j.ica.2009.06.034

2. E.B. Bauer, A.A. Haase, R.M. Reich, D.C. Crans, and F.E. Kühn, Coordination Chemistry Reviews, 393, 79(2019), DOI: 10.1016/j.ccr.2019.04.014

3. A. Naor-Pomerantz, N. Eliaz, and E. Gileadi, Electrochimica Acta, 56(18), 6361(2011), DOI: $10.1016 /$ j.electacta.2011.05.022

4. E. Dallerba, M. Massi, and A. Lowe, European Polymer Journal, 126, 150(2020), DOI: 10.1016/j.eurpolymj.2020.109559 
RASĀYAN J. Chem.

Vol. 14 | No. 2 |728-734| April - June | 2021

5. L. Lei, D. Huang, G. Zeng, M. Cheng, D. Jiang, C. Zhou, S. Chen, and W. Wang, Coordination Chemistry Reviews, 399, 213020(2019), DOI:10.1016/j.ccr.2019.213020

6. J. Bautista-Ruiz, J. Caicedo and A. Chaparro, Rasayan Journal of Chemistry, 12(4), 1950(2019), DOI: 10.31788/RJC.2019.1245390

7. T. Hong, M. Liu, J. Ma, G. Yang, L. Li, K. Mumford, and G. Stevens, Separation and Purification Technology, 236, 116281(2020), DOI:10.1016/j.seppur.2019.116281

8. U. Kesieme, A. Chrysanthou, and M. Catulli, International Journal of Refractory Metals and Hard Materials, 82, 150(2019), DOI: 10.1016/j.ijrmhm.2019.04.006

9. Q. Huang, and T. Lyons, Electrochemistry Communications, 93, 53(2018), DOI: 10.1016/j.elecom.2018.06.003

10. Y. Abdelrahman, M. Gepreel, S. Kobayashi, S. Okano, and T. Okamoto, Materials Science and Engineering: C, 99, 552(2019), DOI: 10.1016/j.msec.2019.01.133

11. J. Bautista-Ruiz, W. Aperador and J. Olaya, Rasayan Journal of Chemistry, 11(2), 597(2018), DOI: $10.31788 /$ RJC.2018.1122075

12. A. Ścibior, Ł. Pietrzyk, Z. Plewa, and A. Skiba, Journal of Trace Elements in Medicine and Biology, 61, 126508(2020), DOI:10.1016/j.jtemb.2020.126508

13. M. Nicoara, A. Raduta, R. Parthiban, C. Locovei, J. Eckert, and M. Stoica, Acta Biomaterialia, 36, 323(2016), DOI: 10.1016/j.actbio.2016.03.020

14. W. Aperador, J. Duque, and E. Ruiz, Advanced Materials Research, 1016, 320(2014), DOI: $10.4028 / \mathrm{www}$.scientific.net/amr.1016.320

15. D.T. Wee, J.N. Chen, Y. Huang, P. Wong, H. Liang, S.S. Venkatraman, and H. Ying, Acta Materialia, 185, 60(2020), DOI:10.1016/j.mtla.2020.100727

16. J. Rau, A. Latini, A. Generosi, V. Rossi Albertini, D. Ferro, R. Teghil, and S.M. Barinov, Acta Materialia, 57(3), 673(2009), DOI:10.1016/j.actamat.2008.10.009

17. J. Zhang, Y. Liu, X.H. Long, and X.L. Wang, Surface and Coatings Technology, 366, 131(2019), DOI: 10.1016/j.surfcoat.2019.01.120

18. W. Aperador, M. Torres, and E. Ruiz, E. Applied Mechanics and Materials, 598, 13(2014), DOI: $10.4028 / w w w . s c i e n t i f i c . n e t / a m m .598 .13$

19. S. Agiladevi, and S. Rajendran, Rasayan Journal of Chemistry, 12(1), 22(2019), DOI: $10.31788 /$ RJC.2019.1215037

20. F. Sun, Y. Wang, L. Fang, X. Yang, W. Fu, D. Tian, Z. Huang, J. Li, H. Zhang, and Y. Wang, Applied Catalysis B: Environmental, 256, 117851(2019), DOI:10.1016/j.apcatb.2019.117851

21. V.V. Kuznetsov, Yu.D. Gamburg, V.V. Zhulikov, R.S. Batalov, and E.A. Filatova, Electrochimica Acta, 317, 358(2019), DOI:10.1016/j.electacta.2019.05.156

22. S. Szabó, and I. Bakos, Corrosion Science, 43(5), 931(2001), DOI:10.1016/S0010-938X(00)00110-4

23. J. Bautista-Ruiz, W. Aperador and C. España, Desgaste Abrasivo y Corrosivo de Recubrimientos TiN/TiAlN y TiN/AlTiN, Eae-publishing, Madrid, p.58,77(2011).

24. Y. Tong, S. Bai, H. Zhang, and Y. Ye, Applied Surface Science, Volume 261, 390(2012), DOI: 10.1016/j.apsusc.2012.08.020

25. G. Soto, H. Tiznado, J.A. Díaz, E.C. Sámano, and A. Reyes-Serrato, Thin Solid Films, 519(10), 3236(2011), DOI: 10.1016/j.tsf.2011.01.190

[RJC-6046/2020] 